\title{
ENFERMEIRAS NO RITO DE PASSAGEM DE GETÚLIO DOS SANTOS (1929)
}

\author{
Simone Aguiar ${ }^{1}$, Tainara Veraldo ${ }^{1}$, Claudia $\mathrm{Cruz}^{2}$, Sandra Goulart ${ }^{3}$, Fernando Porto ${ }^{4}$
}

\begin{abstract}
RESUMO: Estudo de perspectiva na micro história teve por objetivo discutir o rito de passagem do Diretor da Escola Prática de Enfermeiras da Cruz Vermelha Brasileira - Órgão Central - Rio de Janeiro, Getúlio dos Santos, em 1929. O método utilizado foi da microanálise, por meio de duas imagens e sua legenda sobre o momento do rito de passagem de Getúlio dos Santos veiculadas na página da Revista da Semana. O resultado da análise ocorreu mediante aplicação de uma matriz de análise com base na semiótica nos planos de expressão e conteúdo, evidenciando a presença de enfermeiras uniformizadas ao ter atitude de zelo e desvelo diante do corpo morto. A conclusão apontou para mais um elemento simbólico que contribuiu para o entendimento da construção da imagem pública da enfermeira com reflexo para a identidade profissional.
\end{abstract}

DESCRITORES: Enfermagem; História da enfermagem; Morte.

\section{NURSES IN THE RITE OF THE PASSING OF GETÚLIO DOS SANTOS (1929)}

ABSTRACT: This study with the perspective of microhistory aimed to discuss the rite of the passing of the Director of the Brazilian Red Cross Nurses' Practice School - Central Department - Rio de Janeiro, Getúlio dos Santos, in 1929. The method used was micro-analysis, through two images and its caption on the occasion of the rite of passing of Getúlio dos Santos shown on the page of the Revista da Semana. The result of the analysis took place through the application of an analysis matrix based on the semiotics in the planes of expression and content, evidencing the presence of uniformed nurses, through their attitude of care and concern regarding the dead body. The conclusion pointed to one more symbolic element which contributed to the understanding of the public image of the nurse, reflecting the professional identity.

DESCRIPTORS: Nursing; History of Nursing; Death.

\section{ENFERMERAS EN EL RITUAL DE PASAJE DE GETÚLIO DOS SANTOS (1929)}

RESUMEN: Estudio de perspectiva de la micro historia cuyo objetivo fue discutir el ritual de pasaje del Director de la Escuela Práctica de Enfermeras de la Cruz Roja Brasileña - Institución Central - Rio de Janeiro, Getúlio dos Santos, en 1929. El método utilizado fue del microanálisis, por medio de dos imágenes su subtítulo sobre el momento del ritual de pasaje de Getúlio dos Santos presentes en la página de la Revista da Semana. El resultado del análisis ocurrió por medio de aplicación de una matriz de análisis con base en la semiótica en los planes de expresión y contenido, evidenciando la presencia de enfermeras uniformadas con actitud de cuidado y desvelo delante del cuerpo muerto. Se concluyó que hay más un elemento simbólico que contribuye para el entendimiento de la construcción de la imagen pública de la enfermera con reflejo para la identidad profesional.

DESCRIPTORES: Enfermería; Historia de la enfermería; Muerte.

${ }^{1}$ Enfermeira. Mestranda pelo Programa de Pós-Graduação Mestrado em Enfermagem da Escola de Enfermagem Alfredo Pinto - UNIRIO. Membro dos Grupos de pesquisa do Laboratório de Pesquisa em História da Enfermagem - LAPHE e Laboratório de Abordagens Científicas na História da Enfermagem - LACENF.

${ }^{2}$ Enfermeira Coordenadora de Enfermagem do Centro de Terapia Intensiva do Hospital Universitário Gafree e Guinle. Membro do LAPHE e LACENF.

${ }^{3}$ Nutricionista. Doutoranda pelo Programa de Pós-Graduação Doutorado em Enfermagem e Biociências da Escola de Enfermagem Alfredo Pinto - UNIRIO. Professora do Departamento de Nutrição em Saúde Pública da Escola de Nutrição da UNIRIO. Membro do LAPHE e LACENF.

${ }^{4}$ Enfermeiro. Doutor em Enfermagem. Professor da Escola de Enfermagem Alfredo Pinto e dos Programas de Pós-Graduação em Enfermagem e Biociências da Escola de Enfermagem Alfredo Pinto. Membro do LAPHE e LACENF.

Autor correspondente:

Recebido: 09/07/2012

Claudia Cruz Aprovado: 09/05/2013

Hospital Universitário Gafree e Guinle

RuaVelindaMauríciodaFonseca,65-20785-210-RiodeJaneiro-RJ-Brasil

E-mail: ccs.claudiacruz@gmail.com 


\section{INTRODUÇÃO}

Muitos são os ritos que as enfermeiras brasileiras passam e/ou vivenciam na formação e na trajetória profissional. Dentre eles, pode-se citar a imposição da touca e o rito de formatura ${ }^{(1)}$. No presente estudo a proposta de objeto é o rito de passagem do Diretor da Escola Prática de Enfermeiras da Cruz Vermelha Brasileira - Órgão Central - Rio de Janeiro, Getúlio dos Santos, publicado na Revista da Semana em 05 de janeiro de 1929.

A Cruz Vermelha Brasileira foi criada em 5 de dezembro de 1908, anos mais tarde, em 1914, no período da I Guerra Mundial, foi criado o Curso de Enfermeiras Voluntárias para atender os interesses do país. Este serviu como base para a criação do Curso de Enfermeiras Profissionais e, simultaneamente, a inauguração da Escola Prática de Enfermeiras da Cruz Vermelha Brasileira, sob a direção do secretário geral da instituição, o médico Dr. Getúlio dos Santos ${ }^{(2)}$.

Pelo que se sabe em estudo realizado, Getúlio dos Santos era formado em Medicina e foi diretor da Escola Prática de Enfermeiras da Cruz Vermelha Brasileira, como também exerceu o cargo de Secretário Geral da Instituição e além de ser Oficial do Serviço de Saúde do Exército. Publicou a obra intitulada Livro do Enfermeiro e da Enfermeira - para uso dos que se destinam à profissão de enfermagem e das pessoas que cuidam de doentes, com edições em 1916, 1918 e 1928. Nesta trajetória, foi um profissional altruísta e entusiasta no desenvolvimento da profissionalização da Enfermagem brasileira $^{(2)}$.

Ele acreditava que deveria investir na formação da enfermagem para que fosse possível qualificar o cuidado prestado nos hospitais e domicílios pelas "enfermeiras leigas", substituindo-as por enfermeiras profissionais, foi quando a Cruz Vermelha Brasileira apresenta a expressão Enfermeira Diplomada, em 1923, no sentido de diferenciá-las no campo da profissão(1) ${ }^{(1}$.

Com o seu passamento, a despedida do corpo de Getúlio dos Santos ocorreu no Palácio da Cruz Vermelha Brasileira - Órgão Central - no Rio de Janeiro, com o comparecimento de autoridades civis, militares, políticos e as enfermeiras que durante anos foram suas aspirantes, como uma das maneiras de agradecer o que ele teria feito em prol de suas formações. Foi neste clima de despedida que ocorreu o rito de passagem de Getúlio dos Santos, veiculado na Revista da Semana.

O presente estudo tem por objetivo discutir o rito de passagem do Diretor da Escola Prática da
Cruz Vermelha Brasileira. A justificativa para a sua realização deve-se à possibilidade do entendimento do mecanismo da construção da imagem pública da enfermeira brasileira. Nesta perspectiva, se passa a entender melhor a construção da identidade profissional e como se deu no passado a visibilidade profissional. Outra argumentação possível é a verossimilhança de como a sociedade tinha a oportunidade de ver e crer na enfermagem oriunda daquela instituição de historiografia internacional, cuja missão era de atender os necessitados em tempos de guerra, calamidade e nas necessidades sociais.

Nesta linha de pensamento, é possível conduzir a concepção que até os dias hodierno tenta-se preservar no sentido de cuidar do ser humano, mediante as imagens veiculadas, principalmente, as televisivas.

\section{MÉTODO}

O estudo foi realizado na perspectiva da microhistória, por meio dos indícios e vestígios, no sentido de se investigar de forma microscópica, ou seja, delimitar conjuntos circunscritos em tamanho reduzido ${ }^{(3-4)}$. Neste sentido, foram utilizadas duas imagens e respectiva legenda, todas publicadas em conjunto, na mesma página, como fotorreportagem na Revista da Semana, sendo articuladas à literatura de aderência ao objetivo de estudo.

Nas fotografias, foi aplicada a matriz de análise, que se pode citar, validada por uma tese de doutoramento e quatro dissertações de mestrado no Laboratório de Pesquisa de História da Enfermagem (LAPHE), da Escola de Enfermagem Alfredo Pinto, da Universidade Federal do Estado do Rio de Janeiro, com três itens, a saber: identificação, plano de expressão e conteúdo ${ }^{(1)}$. Ressalta-se que a matriz de análise tem por base conceitual a semiótica, entendida como plano de expressão se refere à manifestação desse conteúdo como um sistema de significação verbal, não-verbal ou sincrético e o plano de conteúdo ao significado do texto. Em outras palavras, o que o texto relata e como ele faz para dizer o que diz - a mensagem ${ }^{(5)}$.

A concepção de rito adotada foi a de conjunto formalizado em certa dimensão simbólica, caracterizado por configuração espaço-temporal, pelo recurso de uma série de objetos, sistemas de linguagens e comportamentos e signos que necessitam ser decodificados para que possam ser entendidos como bem comum do grupo. Cabe destacar que a dimensão simbólica no rito 
é uma linguagem eficaz na medida em que atua sobre a realidade social, não se fazendo de qualquer maneira, já que necessita de apoio simbólico reconhecido pela sociedade $^{(6)}$.

Nesta perspectiva, entendeu-se como rito de passagem a forma de negociação para um novo estatuto dentro de um sistema hierarquizado e estruturado de posições associadas a determinado grupo de indivíduos, que coadunam dos mesmos princípios. Ademais, o rito se distingue em três estados: separação, margem e agregação. Para o presente estudo se delimitou o estado de separação por se tratar de cerimônia fúnebre, enquanto que o de agregação se refere ao de casamento e o de margem, exemplificado pelo noivado ${ }^{(6)}$.

Nesta linha de pensamento, foram aplicadas as imagens, a concepção de rito, a dimensão simbólica e o estado que foram discutidas no sentido de atender ao objetivo proposto, envolvendo a construção do mecanismo da imagem da enfermeira brasileira na perspectiva da microanálise.

\section{RESULTADOS}

As imagens veiculadas na Revista da Semana tratam de vestígios do rito de passagem de Getúlio dos Santos. A figura 1 trata da temática do velório, em formato retangular, de pouca nitidez, em ambiente interno - dependência do Palácio da Cruz Vermelha Brasileira, no Rio de Janeiro, cenário natural e interno. Nessa imagem foram retratados 7 homens em trajes sociais e 11 mulheres - destas, pelo menos quatro ostentando uniformes da Cruz Vermelha Brasileira - vestido e véu na cor clara e o símbolo da cruz na frente na cor escura - e as demais, do grupo feminino, em trajes sociais com chapéus em tons de cinza.

Os atributos de paisagem foram compostos de cinco castiçais com longas velas acessas. Ao centro do texto imagético é possível visualizar a urna funerária de Getúlio dos Santos, rodeada pelos presentes. O cenário parece conter flores em cima da urna, ou trata-se do corpo coberto por flores.

A expressão corporal das pessoas no ambiente

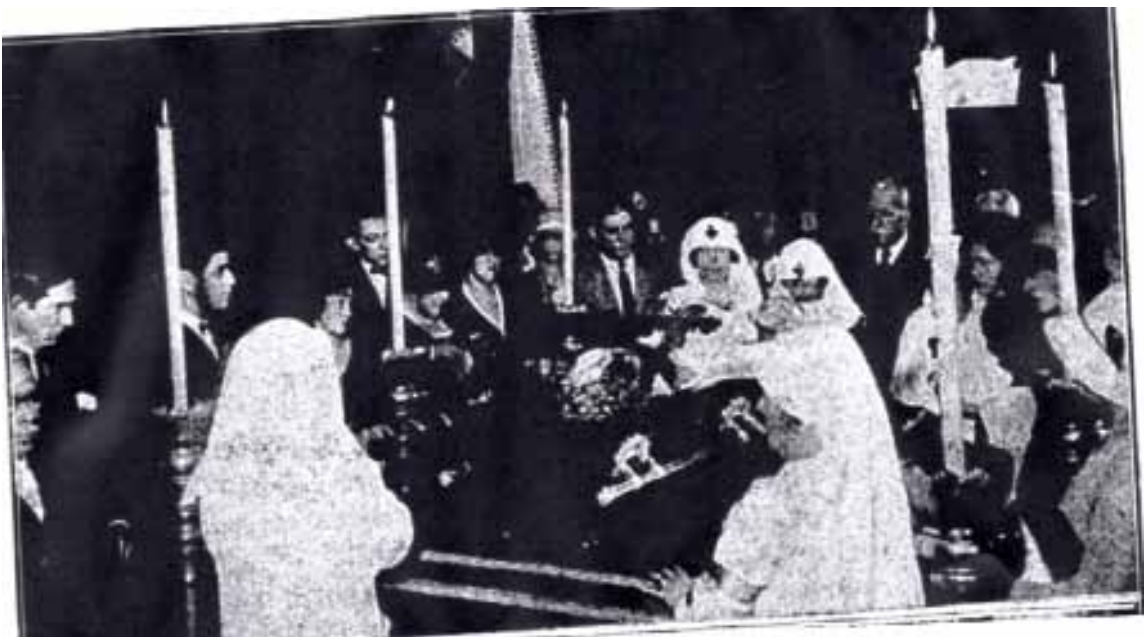

Figura 1 - Velório do Sr. Getúlio dos Santos. Rio de Janeiro, 1929

Fonte: Revista da Semana, 5 de dezembro de 1929

deixa transparecer a significação de despedida, algumas se apresentam de cabeça baixa e quiçá chorando. A imagem não deixa transparecer ser posada, mas sim flagrante do momento, até mesmo porque não se identificou a presença de olhares diretos para a lente da câmera fotográfica. $O$ texto fotográfico narra, simbolicamente, um momento do rito de passagem, que pelo efeito de claridade ${ }^{(1)}$, por meio dos uniformes das enfermeiras, oferece destaque, em especial pela pouca nitidez da imagem ou, também, pode se inferir a pouca claridade do ambiente no momento da fotografia.

Cabe destacar que, por volta 1850 , os cientistas descobriram que a combustão de filamentos de magnésio produzia uma luz brilhante. Em 1887, os alemães
Adolf Mietke e Johannes Gaedicke desenvolveram um flash que iluminava, por meio da mistura de magnésio, cloreto de potássio e sulfeto de antimônio, o qual, apesar do perigo, agradou aos fotógrafos à época e com o decorrer dos anos. Em 1923, Harold Edgerton inventou o flash fotográfico, mas sua aplicabilidade na prática fotográfica somente se deu na década de $1930^{(7)}$.

Quanto ao rito, este foi capturado pela lente fotográfica no sentido de exorcizar o perigo. Dito de outra maneira, capturou fragmentos do tempo no espaço da separação do indivíduo de seu antigo estatuto, de forma pública, posicionando-o em uma nova condição ${ }^{(6)}$. Isto significa que a imagem capturada pode ser considerada um congelamento do real para realidade revelada pela 
imagem fotográfica, sobre a despedida de um estatuto do morto no grupo e no mesmo momento, colocando-o em outra posição, que se pode denominar de vulto histórico. Na figura 2 foi possível identificar no rito outro momento do congelamento do tempo e no espaço, ou seja, a saída da urna funerária da Instituição. A imagem é, possivelmente, do tipo posada, mesmo considerando que diversas pessoas se encontram olhando para frente, o que é possível inferir a posição do fotógrafo com sua máquina fotográfica. A fotografia foi editada no formato geométrico retangular, ambiente externo e natural, provavelmente, em uma das ruas adjacentes à Instituição, pela presença e organização dos automóveis da época.

As pessoas retratadas são de grupo misto, ficando arriscada a quantificação dos presentes, pois se trata de

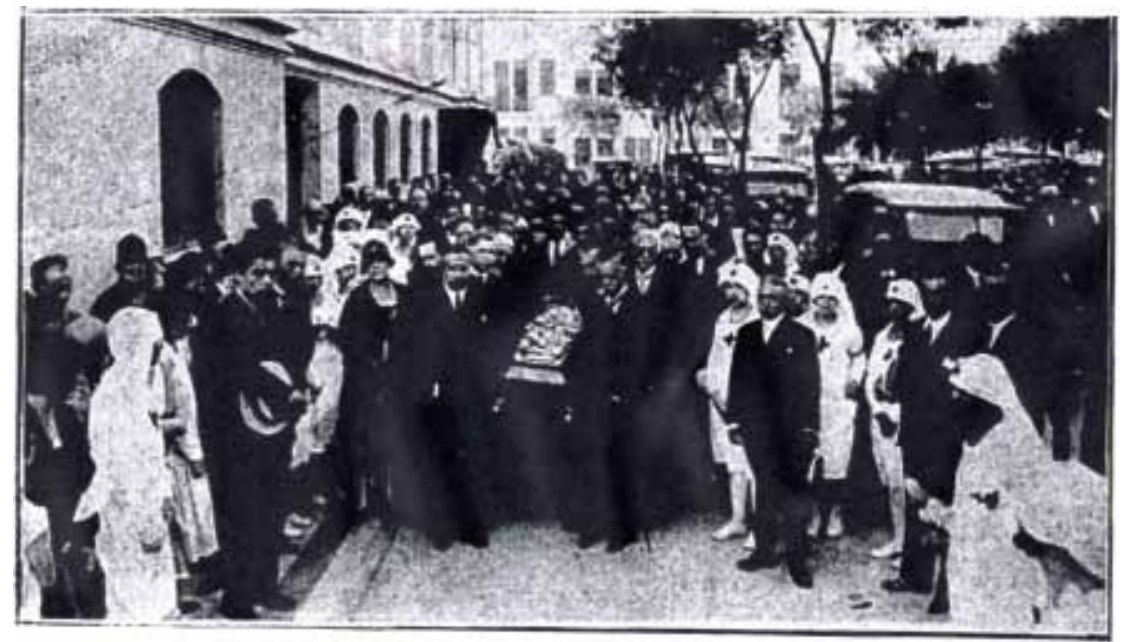

Figura 2 - Saída da urna funerária do Sr. Getúlio dos Santos do Palácio da Cruz Vermelha Brasileira - Rio de Janeiro, 1929 Fonte: Revista da Semana, 5 de dezembro de 1929

plano geral. Mas, o quantitativo de enfermeiras retratadas é de treze, pelo relevo da cor clara dos uniformes com o símbolo da cruz.

Os atributos de paisagem são árvores carros, paredes da edificação, provavelmente, da Instituição e ao centro do texto imagético a urna ataúde, sendo transportadas por algumas autoridades, apresentadas na legenda da fotografias, abaixo trasncrita:

A câmara ardente do dr. Getúlio dos Santos, secretário da Cruz Vermelha Brasileira, e o sabimento da urna funerária do edifício dessa grande instituição nacional. Veêm-se entre outro, carregando o ataúde, os srs, ministro Octavio Mangabeira, senador Epitacio Pessôa, general dr. Ivo Soares, marechal Mendes de Moraes, ministro general Nestor dos Passos e tenente M. Polonia, assistente militar do sr. ministro da Justiça.

Cabe registrar que as legendas são estratégias de editoração que os jornalistas utilizam no sentido de fazer com que os leitores direcionem os seus olhares para aquilo que interessa, segundo a intenção dos editores do periódico. Chama atenção que este tipo de estratégia é conhecido, à luz de Bourdieu, no sentido de que eles se utilizam de óculos especiais. O mesmo autor afirma que a fotografia, nestes casos, não é nada sem a legenda ${ }^{(8)}$. Nesta perspectiva, a legenda se torna instigante para se investigar, pois estudo possibilitou evidenciar outra interpretação, distinta daquela proposta pelo editorialista do periódico ${ }^{(1)}$. No caso das imagens e da legenda presentes no estudo, não foi possível identificar divergências que foram expostas, seja no texto escrito ou no imagético.

\section{DISCUSSÃO}

As três imagens - duas fotografias e uma de texto escrito - são vestígios do rito de passagem no estado de separação. Mas, o que tem ele haver com o passamento de um médico para construção do mecanismo da imagem da enfermeira? A resposta imediata seria: a presença das enfermeiras no rito. Mas isso não atende à microanálise, pois se faz necessário um olhar mais atento sobre a articulação dos textos escrito, imagéticos e o contexto.

Nas fotografias destacam-se o uniforme, o símbolo da cruz, as velas acessas, a postura das uniformizadas, a presença das autoridades civis, políticas e militares, em 
especial ao conduzirem a urna funerária com Getúlio dos Santos e a legenda. Neste sentido, o uniforme é como marca de distinção, também, que pode ser entendido como parte do rito no estado de separação, pois quem o usa perde, simbolicamente, a sua identidade corporal ${ }^{(6)}$.

Isto conduz ao entendimento que as enfermeiras ao usarem seus uniformes da Cruz Vermelha Brasileira, naquele momento do rito de passagem não se tratavam de simples mulheres, mas sim de agentes institucionais, pelas assinaturas imagéticas impressas em seus $\operatorname{corpos}^{(2)}$.

O símbolo da cruz é uma das marcas simbólicas de nexus com a enfermagem, mas de presença marcante, por meio da evidência pela institucionalização da Cruz Vermelha, seja pela representação visual, bem como pela regulamentação do símbolo da cruz em formato e na cor vermelha pela Instituição ${ }^{(2)}$.

As velas acesas remete à chama da lâmpada, símbolo da Enfermagem moderna, introduzida nos ritos da profissão no Brasil, em 1925, de forma pública na formatura da primeira da Escola de Enfermeiras do Departamento Nacional de Saúde Pública, atual Escola de Enfermagem Anna Nery, da Universidade Federal do Rio de Janeiro. Ocasião na qual a lâmpada foi acessa e passou de mão em mão pelas formandas, tendo registro na imprensa ilustrada. O significado da chama, segundo a pesquisa, é manter viva a memória de Florence Nightingale, percussora da Enfermagem Moderna ${ }^{(2)}$.

A postura das enfermeiras em torno da urna, nas duas imagens, pode ser entendida como saudade e deferência aos feitos de Getúlio dos Santos à Instituição e, principalmente, à Escola Prática de Enfermeiras da Cruz Vermelha Brasileira - Órgão Central, Rio de Janeiro, mas também de zelo pelo corpo morto. Neste sentido, as enfermeiras ao velarem o corpo de Getúlio dos Santos, demonstram o cuidado aprendido e praticado no rito de passagem do tipo separação, entendido como, quiçá, o início da preservação da memória social, em especial, da Saúde Pública ${ }^{(9)}$.

O passamento de Getúlio dos Santos trata-se do descanso do corpo biológico. Por outro lado, se refere posicioná-lo em outro estatuto, ou seja, a preservação da memória social, em especial, quando o nome é citado, representado, lembrado pelas mais diversas maneiras, dentre elas, verbalizada, escrita, representada no sentido de fazê-lo vivo socialmente.

A presença das autoridades no texto imagético é ratificada com seus nomes na legenda, sendo um dos elementos que se faz necessário à legitimação do rito, pois evidência o poder as autoridades presentes. Em outras palavras, o rito não pode ser auto-administrado, pois ele necessita de autoridades presentes sejam eles, militares, políticos, religiosos, ou representantes leigos reconhecidos de poder relativo ao rito ${ }^{(6)}$. Nesta perspectiva, depreendeu-se que o rito transmitiu, pelas imagens veiculadas na página da Revista da Semana, o efeito de rito de passagem no estado de separação, considerados de pouca publicização, exceto quando se trata de nomes reconhecidos pela sociedade, por serem autônomos ${ }^{(6)}$.

No caso das imagens veiculadas na Revista da Semana, elas integram o morto ao mundo dos mortos e costumam ser mais elaboradas, o que lhe distingue e o atribui poder e prestígio. Exemplo disto é a vigília com a presença dos amigos e familiares. No caso do estudo, acrescenta-se a figura das enfermeiras, identificadas pela ostentação dos uniformes institucionais, que ao mesmo tempo na fotografia causaram o efeito de claridade, dando relevo ao rito de passagem.

\section{CONCLUSÃo}

As imagens do rito de passagem no estado de separação de Getúlio dos Santos com a presença das enfermeiras da Cruz Vermelha Brasileira revelaram o zelo e desvelo a quem parte do mundo dos vivos para dos mortos.

Neste sentido, as imagens contribuem com a construção do mecanismo da imagem da enfermeira, quando a sociedade tem oportunidade de ver e crer na prática da enfermagem. Isto significa que o cuidado prestado de fato é, e deve ser estendido mesmo diante do corpo morto.

Este cuidado foi e é verossímil na prática da profissão da enfermagem, podendo ser acentuado nos mais sensíveis, independemente do credo, mas em respeito à vida, que no caso do estudo, a passagem da vida biológica para a preservação da memória social.

A imagem discutida é mais uma das facetas que se pode inferir na construção da imagética pública da enfermeira brasileira. Resultado de pesquisa, que se entendeu ser relevante na compreensão, mas, também, para o entendimento da identidade profissional.

\section{REFERÊNCIAS}

1. Porto F, Santos TCF. A enfermeira brasileira na mira do click fotográfico (1919-1925). In: Porto F. Amorim $\mathrm{W}$, organizadores. História da enfermagem brasileira. Rio de Janeiro: Águia Dourada; 2007. p. 25-188.

2. Barbosa AC, Porto F. A Escola Prática de Enfermeiras da Cruz Vermelha Brasileira na imprensa escrita 
(1916-1917). Rev Pesquisa: Cuidado é fundamental. 2006;10(3):90-4.

3. Porto F, Santos TCF. O rito e emblemas na formatura das enfermeiras brasileiras no Distrito Federal (19241925). Esc. Anna Nery. 2009;13(2):249-55.

4. Revel J. Jogos de escalas - a experiência da microanálise. $1^{\mathrm{a}}$ ed. Rio de Janeiro: Fundação Getulio Vargas; 1998. p. 264.

5. Pietroforte AV. Semiótica Visual - os percursos do olhar. $1^{a}$ ed. São Paulo: Contexto; 2004. p. 164.

6. Segalen M. Ritos e rituais. $1^{\mathrm{a}}$ ed. Rio de Janeiro: Contemporâneos. FGV; 2002. p. 161.

7. Duarte M. O livro das invenções. $1^{\mathrm{a}}$ ed. São Paulo: Companhia das Letras; 1997. p. 422.

8. Bourdieu P. Sobre a televisão - seguido de a influência do jornalismo e os jogos olímpicos. Rio de Janeiro: Jorge Zahar;1997. p. 143.

9. Larocca LM, Marque VRB. Quando a higiene se torna pública: saúde e estado. Cogitare enferm. [Internet] 2005;10(1) [acesso em 29 mai 2012]. Disponível: http://ojs.c3sl.ufpr.br/ojs2/index.php/cogitare/article/ view/4682/3629. 